\title{
Soundless Video Advertising and Purchase Decisions: An Experiment Study With and Without Sound
}

\author{
Febby Permata Oktavia ${ }^{1}$ Sudarto Sudarto ${ }^{1}$ Rezi Erdiansyah ${ }^{1 *}$ \\ ${ }^{1}$ Faculty of Communication, Universitas Tarumanagara, Jakarta 11440, Indonesia. \\ "Corresponding author. Email: rezie@fikom.untar.ac.id
}

\begin{abstract}
The increasing intensity of social media use is greatly utilized by business actors to advertise their products through social media. But it is estimated that between $82 \%-94 \%$ of social media users watch videos without using their voice. This can affect the effectiveness of advertising on purchasing decisions. This research was conducted with the aim of testing the results when the audience watched the video with sound or without sound on purchasing decisions, seeing if there were differences in the results of exposure to the video, and testing whether the long duration of the video without sound was more successful than the short duration. To investigate this, the researcher used an experimental quantitative approach with a $2 \times 4$ factorial design. 140 respondents were taken randomly according to the criteria, using random assignment techniques to determine the research group. The theory used in this research is soundless video advertising, information processing theory, and purchasing decisions. The results showed that in general, there was no difference in exposure to silent advertisements with sound advertisements (product advertisement, talent advertisement, and horror trailers), except for comedy trailers. Also, it can be seen that long duration of silent videos are more successful than short duration videos in purchasing decisions.
\end{abstract}

\section{Keywords: Soundless Video Advertising, Purchase Decisions, Experimental Studies}

\section{INTRODUCTION}

Indonesia has 150 million internet users in 2019. This number increased by $13 \%$ or 17 million users from 2018 . With the increasing number of internet users, the number of social media users is also increasing. The platforms often used by Indonesians are Youtube (88\%), Whatsapp (83\%), Facebook (81\%), and Instagram (80\%) [1].

The high intensity of use of social media platforms in Indonesia is a greatest opportunity for advertisers to use social media as a medium to influence consumer purchasing decisions. According to the history of online advertising, online advertising was first created in the form of banners in 1994. The interest of users in this audio-visual media encouraged advertisers to switch to interactive audio visual (video) ads [1]. Video advertising is a form of online advertising that's growing at this time [2]. This is not surprising given that millennials and adolescents each watch 64 percent less television than adults aged 35 and over [2].

Taking advantage of the popularity of online video, advertisers are placing video ads in more places on social media, but according to advertising agencies it is estimated that between $82 \%$ - $94 \%$ of social media users watch videos without using the sound [2]. This can affect the effectiveness and meaning of the message in advertisements and can reduce the decision of potential consumers to buy products [2].
So Campbell \& Pearson, 2019 created a strategy to produce successful soundless video advertising, by using visual storytelling, reference to shared understanding (emotional response), increasing intensity of visual or energy, avoiding or using tactical subtitles [2].

This paper uses soundless video advertising theory from Campbell \& Pearson (2019) paper, which discusses strategies for creating successful of soundless video advertising by using visual storytelling, reference to shared understanding (emotional response), increasing intensity of visual or energy, avoiding or using tactical subtitles [2].

Then to process information from soundless video advertising, researchers use information processing theory, namely the SOR theory which discusses human behavior (R) directly or indirectly influenced by the physical environment $(\mathrm{S})$. Then the human emotional state $(\mathrm{O})$ as a mediation between the relationship of the environment and human action [3]. And elaborate likelihood theory which discusses how communicators process a persuasive message by going through two routes, namely central route and peripheral route [4].

After processing a persuasive message, individuals usually produce some behaviors. In this paper researchers are using purchasing decisions as a reflection of human behavioral responses after a stimulus is given. The purchasing decision is a series of changes in making purchasing decisions, including the determination of the purchase of a good / service with various alternative choices. Advertising can 
lead to purchase decisions. That one of the factors of purchasing decisions on products is due to the attractiveness of advertising, the quality of advertising messages and brand trust [5].

Based on the descriptions that have been presented, the problem can be formulated as follows: "Are there differences in the results of exposure to video ads with sound and soundless on a purchase decision? "

\subsection{Related Work}

\subsubsection{Strategies for Creating Successful Soundless Video Advertisement}

Video advertising is increasingly prevalent, appearing in more and more places across the web and social media. These advertisement are often viewed without using the sound, which may affect their effectiveness and meaning [2]. So this paper are discusses how to create a successful video advertisement without using sound. By using qualitative research methods in researching and analyzing advertisements taken from articles and agency data sets. In addition, researchers also interviewed professional advertising agencies who have experience with soundless video to build a new understanding of the phenomenon of soundless video advertising. The analysis in this paper reveals four related operational strategies and tactics that advertisers can employ to develop more successful advertisements for soundless environment. Soundless video advertisement must using visual storytelling, reference to shared understanding (emotional response), increasing intensity of visual or energy, avoiding or using tactical subtitles [2].

\subsubsection{Exploring Short Video with the Stimulus- Organism-Response Model}

This study aims to extend the Stimulus-Organism-Response (S-O-R) model to the context of social media and validate the positive influence between short videos, goal images, perceived interactivity, and short videos of app user visit intentions [6]. Independent variables in this study consisted of video quality, video credibility, cognitive image, affective image and the dependent variable in this study was perceived interactivity and visit intention. The approach method in this study is a quantitative research method with data collection techniques through online surveys using PLS-SEM analysis. The results of the study $(n=236)$ showed that the quality of the video had a significant effect on cognitive and affective image of the video goals, and the perceived interactivity significantly affected the audience's behavioral intentions [6].

\subsubsection{Advertising Appeal and Purchase Decisions}

In this era of globalization, advertising is one of the important things in marketing a product. Advertisements that are displayed must be able to appear attractive and persuasive. So that the researchers are interested in discussing the analysis of advertising factors that influence consumers on purchasing decisions [5], [7]. Dennyka revealed that the attractiveness of advertisements on Youtube greatly influences consumer purchasing decisions with the results of the linear regression equation from his research of $Y=2.025+0.475 X$ [7]with advertising appeal as independent variable and purchase decision as dependent variable [7], this statement was also expressed by Gunawan who revealed that the factors of advertising attractiveness, quality of advertising messages and brand trust are the factors that can influence consumer purchasing decisions [5] with advertising appeal, quality of advertising messages, and brand trust as independent variables and purchase decision as dependent variable [5].

\subsection{Our Contribution}

This paper presents some experimental results of soundless video advertising on purchasing decisions. However soundless video advertising research has received less attention in the study of advertising science. This paper will provide a deeper understanding and enrich studies regarding soundless video advertising in the digital era.

This study also tested the assumption in Campbell and Pearson's research that long videos were more successful than short videos [2] through an experiment. The results of this experiment can serve as a theoretical basis for future research on soundless video advertising.

\subsection{Paper Structure}

The rest of the paper is organized as follows. Section 1 discusses the phenomenon of soundless video advertising, related work, and the contribution of this paper. Section 2 describes the hypotheses of this paper. Section 3 discusses the research methods used by researchers to test the phenomenon of soundless video advertising. Then, the framework and instrument are extended to findings and discussions in Section 4. Finally, Section 5 is the conclusion of this paper.

\section{BACKGROUND}

According to Campbell \& Pearson, 2019 attractive and successful soundless video ads are advertisements that use visual storytelling, reference to shared understanding (emotional response), highlight visual or energy intensity, avoid or use tactical subtitles [2]. Emphasis on facial expressions, body movements, the use of lighting, camera techniques, objects in the shot, and editing are creative tools used to develop visuals and interest, even without sound [2]. So when the visual are powerful, the sound effect doesn't really matter. So this research can lower the hypothesis as follows:

H1.1a : There's a difference between soundless and sound video advertising on interest. 
H1.0a : There's no difference between soundless and sound video advertising on interest.

As stated in the previous literature, the key of soundless video advertising is visual and simple message delivery [2]. Soundless video advertising would ideally be created by accentuating the visuals rather than telling them verbally. Apart from visuals, soundless video advertising utilizes existing shared knowledge (emotional response) extensively so that the audience has the same understanding [2]. Using the experience the audience will convey meaning is faster so that without context or the words spoken, the audience understands the story line that is conveyed in a video [2]. Therefore, this study derives the following hypothesis:

H1.1b : There's a difference between soundless and sound video advertising on understanding.

$\mathrm{H} 1.0 \mathrm{~b}$ : There's no difference between soundless and sound video advertising on understanding.

Soundless video advertising is coupled with the idea of instilling visuals in the minds of the audience. A series of artistic techniques are used to deepen the audience's emotional engagement when watching soundless video advertising by enhancing visual style [2]. This technique is very relevant to attract attention and increase audience motivation [2]. According to Setiadi, 2019 motivation can be interpreted as something that encourages someone to behave [8]. With the emergence of interest and increased motivation from the audience after watching, it can encourage these individuals to be interested in buying the product or watching the advertised film. So this research can lower the hypothesis as follows:

H1.1c : There's a difference between soundless and sound video advertising on the purchase decision.

H1.0c : There's no difference between soundless and sound video advertising on the purchase decision.

According to Harry in Campbell \& Pearson, 2019 public references to famous figures or celebrities can quickly trigger the existing scheme, when soundless video advertising features a famous public figure, the audience will immediately think about their voice [2]. The existence of storylines and famous characters can allow the audience to understand complex concepts quickly. But when information delivery is channeled to highlight a product in the absence of famous celebrities, it is necessary to have visual or energy intensity in the advertisement so as not to cause boredom [2]. Interest in and understanding of soundless and sound advertising will be channeled by highlighting strong visualization, focusing on well-known products and celebrities. So this research can lower the hypothesis as follows:

$\mathrm{H} 2.1 \mathrm{a}$ : There's a difference between product advertising orientation and talent for soundless video advertising.

$\mathrm{H} 2.0 \mathrm{a}$ : There's no difference between product advertising orientation and talent for soundless video advertising. $\mathrm{H} 2.1 \mathrm{~b}$ : There's a difference between product advertising orientation and talent for advetising sound video.

$\mathrm{H} 2.0 \mathrm{~b}$ : There's no difference between product advertising orientation and talent for advetising sound video.
Humor in successful soundless video advertising is limited to visual form, relying on strong and good visual jokes either side by side contrasting images, or images that come out of water ... or slapstick [2]. Because of that, character visualization and shooting are very important components in soundless video advertising. Likewise with videos that are displayed in the horror genre, usually the horror genre emphasizes extremely close-up visual retrieval of characters or objects. For example, extremely close-up of the player's eyes, which describes the fear of what the player is seeing [9]. With the power of the visuals shown in the horror trailer, it will create a feeling of shock, fear, and terror [9]. The funny and spooky atmosphere can be depicted through the visual even without sound. So this research can lower the hypothesis as follows:

H3.1a : There's a difference between the orientation of horror and comedy trailers for soundless video advertising. H3.0a : There's no difference between the orientation of horror and comedy trailers for soundless video advertising. H3.1b : There's a difference between the orientation of horror and comedy trailers for sound video advertising. H3.0b There's no difference between the orientation of horror and comedy trailers for sound video advertising.

Campbell \& Pearson, 2019 assumes that videos that have a long duration are more successful than videos that have a short duration [2]. To test this statement, this study derives the following hypothesis:

H4.1: The short duration of soundless video advertising is more successful than the long duration of soundless video advertising.

H4.0: The long duration of soundless video advertising is more successful than the short duration of soundless video advertising.

\section{METHODS}

In this study, researchers used a quantitative approach with experimental research methods. Experiments are a method used to test a prediction called a hypothesis and prove a cause-and-effect relationship [10]. In this study, the researcher wanted to carry out an experiment to determine the effect and similarity of the results of the video advertisement with sound and without sound on the control group and the experimental group according to the criteria that will be presented in the population and research sample. Because in this study using experiments on two independent variables, the researchers used a $2 \times 4$ factorial design. Through this research design, it will be seen the difference in results between the voice group and the silent group which can be described as follows:

Table 1 Factorial Design $2 \times 4$

\begin{tabular}{|l|c|c|}
\hline \multirow{2}{*}{$\begin{array}{c}\text { Advertising Video } \\
(\mathbf{B})\end{array}$} & \multicolumn{2}{|c|}{ Treatment $(\mathbf{A})$} \\
\cline { 2 - 3 } & Soundless $\left(\mathrm{A}_{\mathbf{1}}\right)$ & Sound $\left(\mathbf{A}_{2}\right)$ \\
\hline Product $\mathrm{Ad}\left(\mathrm{B}_{1}\right)$ & $\mathrm{A}_{1} \mathrm{~B}_{1}$ & $\mathrm{~A}_{2} \mathrm{~B}_{1}$ \\
\hline Talent $\mathrm{Ad}\left(\mathrm{B}_{2}\right)$ & $\mathrm{A}_{1} \mathrm{~B}_{2}$ & $\mathrm{~A}_{2} \mathrm{~B}_{2}$ \\
\hline Horror Trailer $\left(\mathrm{B}_{3}\right)$ & $\mathrm{A}_{1} \mathrm{~B}_{3}$ & $\mathrm{~A}_{2} \mathrm{~B}_{3}$ \\
\hline
\end{tabular}




\section{Comedy Trailer} $\left(\mathrm{B}_{4}\right)$

$\mathrm{A}_{1} \mathrm{~B}_{4}$

$\mathrm{A}_{2} \mathrm{~B}_{4}$

The group in this research was divided into 2 groups, the soundless group as the manipulated group and the sound group as the control group. Each group was given 4 treatments that is exposure from product ad, talent ad, horror trailer, comedy trailer.

The population that the researcher uses in this study is a population that has the following criteria, are around 20-30 years old, and have never watched the video advertisement that the researcher has chosen. Then the sample in this study was selected based on the effect size. If the effect size is unknown, it can be roughly estimated [10]. Because in previous studies the number of effect sizes was not known, the researchers used a weak effect size with a sample of 70 respondents per group, so that the total respondents in this study were 140 respondents.

In collecting data, researchers used a questionnaire that was distributed online via a google form that was included with a video to collect data. In this study, researchers used seven Likert scales. The seven Likert scales are categorized as follows: strongly agree (7), agree (6), quite agree (5), neutral (4), disagree (3), disagree (2), strongly disagree (1). To see group differences in the study, researchers used the one way ANOVA test using the Statistical Product and Service Solutions (SPSS) software version 24. Before testing one way ANOVA, several conditions were needed to continue the test, namely the classic test (normality test), validity test. , reliability test. In addition, the researcher also used the paired sample $t$ test to test whether there was a difference in the mean for the two paired groups.

\section{FINDINGS AND DISCUSSIONS}

As described in the research method, the number of samples in this study were 140 respondents, then carried out a random assignment to determine the research group. In this study, the researcher divided into 2 groups, namely the experimental group (soundless group) and the control group (sound group). After that the research group was given 4 treatments, namely given 4 different videos (product advertisement, talent advertisement, horror trailers, and comedy trailers).

Table 2 Result of One-Way ANOVA Test on group differences

\begin{tabular}{|l|c|c|c|c|}
\hline & $\begin{array}{l}\text { Talent } \\
\text { Ad }\end{array}$ & $\begin{array}{l}\text { Product } \\
\text { Ad }\end{array}$ & $\begin{array}{l}\text { Horror } \\
\text { Trailer }\end{array}$ & $\begin{array}{l}\text { Comedy } \\
\text { Trailer }\end{array}$ \\
\hline Interest (X1) & 0,885 & 0,848 & 0,709 & $0,020^{*}$ \\
\hline $\begin{array}{l}\text { Understanding } \\
\text { (X2) }\end{array}$ & 0,876 & 0,970 & 0,113 & $0.000^{* *}$ \\
\hline $\begin{array}{l}\text { Purchase } \\
\text { Decisions (Y) }\end{array}$ & 0,185 & 0,173 & 0,775 & $0,012^{* *}$ \\
\hline
\end{tabular}

$\mathrm{p}>0.05$, there was no group difference.

The results of the experiments conducted by researchers show that in general soundless video advertising is not different from sound video advertising from product advertisements, talent ads, and horror trailers, except for comedy trailers. This is possible because the comedy trailer video that the researcher chose has humor that is conveyed in words. So that when the sound is removed, understanding when watching the video is not conveyed.

Then in this study it can be seen that in general the orientation of product advertising videos with talent advertising videos does not have a difference both with voice and without voice, except for the attraction factor. The correlation of interest in purchasing decisions in product advertisements is superior to video without sound, while talent ads are superior to videos with voice. This is because the video without sound emphasizes visualization and visual techniques that are not monotonous. So that the silent group is more interested in watching product advertisements because of good visual strength.

From this it can be seen that every individual who watches an advertisement without sound is more focused on the visualization of the ad and has high motivation to seek more information about the advertised product. Meanwhile, individuals who watch advertisements with sound tend to have low motivation to process the information conveyed in an advertisement. With low motivation, it can allow each individual to quickly make judgments on simple instructions, such as his liking for celebrities or liking something on the information presented. So it can be concluded that individuals who watch videos silently process information through the central route while individuals who watch videos with sound process information via peripheral routes.

In addition, this study also proves that there is no difference between the orientation of the horror trailer and the comedy trailer, either with sound or without sound. This is possible because horror video trailers and comedy trailers have a long video duration so that the delivery of the message is more channeled, even though in this study members of the majority of the population prefer the comedy genre to the horror film genre. This is why videos with long duration are more successful than videos with short duration ads.

Table 3 Result of Standardized Coefficient (Beta) Test on Each Video

\begin{tabular}{|c|c|c|c|c|}
\hline & $\begin{array}{c}\text { Talent } \\
\text { Ad }\end{array}$ & $\begin{array}{c}\text { Product } \\
\text { Ad }\end{array}$ & $\begin{array}{c}\text { Horror } \\
\text { Trailer }\end{array}$ & $\begin{array}{c}\text { Comedy } \\
\text { Trailer }\end{array}$ \\
\hline $\begin{array}{c}\text { Purchase } \\
\text { Desicions }\end{array}$ & 0,797 & 0,770 & 0,808 & 0,857 \\
\hline
\end{tabular}

\subsection{Visual Storytelling and Visual Intensity}

Campbell \& Pearson, 2019, p. 7-9 reveals that the confidence of silent video ads is in the delivery of visual storytelling and usually has a visual intensity or energy in the ad [2]. The results prove that the video advertisements for products, talents, and horror trailers in this study do not have differences in the sound results of the videos that are removed. Because the visual strength that fits in the three advertisements keeps interest and understanding channeled even without a sound. Resulting in a positive response from 
the group to purchasing decisions. Meanwhile, the results in the comedy trailer have a difference between the video with sound and without sound, because presentation of visual are less salient.

\subsection{Information Processing}

In the theory of possible routes that determine information is divided into two, namely the central route and the peripheral route. Information processing through central channels has high motivation to assess and weigh information carefully, compare information via peripheral channels with low motivation and quickly create information based on simple clues, such as the data presented [4]. It is shown in the results of this study that the voiceless group is more interested in the group product advertisement with the voice is more interested in the talent advertisement. So it can be ignored that the individual watching the video silently processes the information via the route whereas the individual watching the video with voice processes the information via the peripheral route.

\subsection{Successful Video}

Campbell \& Pearson, 2019 assumes that videos that longer duration are successful than videos that have a shorter duration [2]. This is shown in this study, long duration is more successful than video advertisements with short duration. This research also shows that there is no difference in the orientation of the horror and comedy trailers, both with sound and without sound.

\section{CONCLUSIONS}

The increasing intensity of social media use is greatly utilized by business actors to advertise their products through social media. But it is estimated that between $82 \%$ - $94 \%$ of social media users watch videos without using their voice. This can affect the effectiveness of advertising on purchasing decisions. It turns out that the results of this study prove that in general soundless video advertising is no different from sound video advertising from product advertisements, talent ads, and horror trailers, except for comedy trailers. Then in general, the video orientation of product ads with video for talent ads has no difference both with voice and without voice, except for the attraction factor. In addition, the orientation of the horror trailer and comedy trailer is known that there is no difference between the two videos, either with sound or without sound. Also, it can be seen that long duration of silent videos are more successful than short duration videos in purchasing decisions. So based on the research results, it can be seen that videos that have visual storytelling, emotional response, visual intensity or energy, and tactical of subtitles, if not heard without using sound, are still effective.

\section{ACKNOWLEDGMENT}

This paper is tended independently and not funded. Beside from that, the researcher would like to praise and thank God Almighty for His blessings and mercy, who guided researchers from the beginning to the completion of this paper. Then the researcher also wants to express his deepest gratitude to several parties who have helped and supported the researcher to the end.

\section{REFERENCES}

[1] M. Nursaif, L. Kusdibyo, R. Kania, and K. Kunci, "Analisa Persepsi Konsumen terhadap Iklan Video pada Instagram," p. 1066, 2020.

[2] C. Campbell and E. Pearson, "Strategies for creating successful soundless video advertisements: Speaking volumes through silence," J. Advert. Res., vol. 59, no. 1, pp. 85-98, 2019, doi: 10.2501/JAR-2018-015.

[3] M. House and R. Rajaguru, "Motion Picture-Induced Visual, Vocal and Celebrity Effects on Tourism Motivation: Stimulus Organism Response Model Motion Picture-Induced Visual, Vocal and Celebrity Effects on Tourism Motivation: Stimulus Organism Response Model,” no. October, pp. 37-41, 2014, doi: 10.1080/10941665.2013.764337.

[4] S. W. Littlejohn, K. A. Foss, and J. G. Oetzel, Theories of Human Communication, vol. 11. Waveland Press, Inc., 2017.

[5] S. P. Gunawan and R. Erdiansyah, "Analisis Pengaruh Faktor-Faktor Periklanan Terhadap Keputusan Pembelian Konsumen Traveloka," vol. 2, no. 1, 2018.

[6] M. Li, "Exploring Short Video Application Users ' Visit Intention: Applying the Stimulus-OrganismResponse Model," vol. 15, no. 12, pp. 8-19, 2019, doi: 10.5539/ass.v15n12p8.

[7] D. Dennyka and R. Erdiansyah, "Pengaruh Daya Tarik Iklan Mobile Legends di Youtube Terhadap Keputusan Pembelian Karakter Game Mobile Legends," Prologia, vol. 1, no. 2, pp. 345-350, 2018.

[8] N. J. Setiadi, Perilaku Konsumen: Perspektif Kontemporer pada Motif, Tujuan, dan Keinginan Konsumen, Ketiga. 2019.

[9] C. Dreyer, "Crafting Fear: The Horror Film Trailer," 2018.

[10] A. Myers and C. H. Hansen, Experimental psychology. Cengage Learning, 2011. 